\title{
Metabolism and absorption of toxic glycosides by ruminants
}

\author{
W. MAJAK
}

Author is toxic plant biochemist, Agriculture Canada Research Station, 3015 Ord Road, Kamloops, B.C. V2B8A9.

\begin{abstract}
The cyanogenic glycoside prunasin is the toxic component in a number of browse species (serviceberry, Amelanchier alnifolia, and chokecherry, Prunus virginiana); and glycosides of 3-nitropropanol (NPOH), such as miserotoxin, are the poisonous principle in a number of $\boldsymbol{A}$ stragalus species such as timber milkvetch, $\boldsymbol{A}$. miser var. serotinus. Hydrolysis of the glycosidic bond in rumen contents is the first step in the bioactivation of the glycosides. Diet influences populations of rumen microorganisms and diet may induce the proliferation of bacteria that function in glycoside hydrolysis and detoxification. The absorption of NPOH from the reticulo-rumen was examined in cattle on alíalia hay and corn silage diets. 3nitroproplonic acid (NPA), the lethal metabolite of NPOH, was detected in both plasma and urine. The plasma levels of NPA were reduced when the diet enhanced the rate of $\mathrm{NPOH}$ detoxification in the rumen. The enhancement was achieved with a feed supplement containing nitroethane, a synthetic analogue of NPOH that is much less toxic than the natural toxin. The high levels of NPA in urine $>\mathbf{3 0} \mathrm{ppm}$ ) suggested a procedure for detecting livestock poisoning by nitro-bearing plants. The absorption of hydrogen cyanide (HCN) from the reticulo-rumen was also examined in cattle given sublethal doses of prunasin from serviceberry. Metabolites of $\mathbf{H C N}$ in blood and plasma were detected at low levels $(<5$ ppm) during the initial 6-hour sampling period. High levels of thiocyanate $(<20 \mathrm{ppm})$, a metabolite of $\mathrm{HCN}$, were detected in urine samples collected at 24-48 hours and this also suggested a diagnostic procedure for detecting $\mathrm{HCN}$ poisoning in cattle.
\end{abstract}

Key Words: Astragalus miser, miserotoxin, 3-nitropropanol A melanchier alnifolia, prunasin, cyanide

\footnotetext{
The author gratefully acknowledges the assistance of John Hall who conducted statistical analyses.

Manuscript accepted 28 May 1991.
}

A diverse array of toxic glycosides occurs in higher plants prominent among which are the glucosinolates, the cardenolides, the saponins, and the calcinogenic, carcinogenic, and hypoglycemic glycosides (Cheeke 1989). Glycosides are characterized by the presence of one or more sugars linked to the alcohol or thiol functions of the nonsugar portion of the molecule which is called the aglycone. The sugar portion can be a simple monosaccharide such as glucose, a disaccharide such as gentiobiose, or an oligosaccharide of 3 or more monosaccharide units. The biological activity of a glycoside is usually determined by the chemical nature of the aglycone which can have aliphatic, aromatic, heterocyclic, or steroidal structures. The aglycones may undergo further enzymatic or nonenzymatic transformations to yield toxic metabolites. The present discussion will be restricted to recent studies on the absorption and metabolism of 2 glycosides, namely prunasin (Dmandelonitrile $\beta$-D-glucoside), a cyanogenic glucoside found in serviceberry (Amelanchier alnifolia) and chokecerry (Prunus virginiana) and miserotoxin (3-nitro-1-propyl $\beta$-D-gluoside), an aliphatic nitrotoxin in timber milkvetch (Astragalus miser var. serotinus) and other Astragalus species. These 2 glycosides show very different mechanisms of metabolism and absorption from the reticulo-rumen.

\section{Miserotoxin}

Metabolism and Absorption

Miserotoxin and its aglycone, 3-nitropropanol (NPOH) have been detected in about 50 species and varieties of Astragalus (Leguminosae) primarily from the temperate regions of North and South America (Williams and Gómez-Sosa 1986; Williams 1982). The poisonous varieties of timber milkvetch, such as $A$. miser var. serotinus, can synthesize high concentrations of miserotoxin exceeding 5\% of the forage dry matter (Quinton et al. 1989). Two metabolic steps are involved in the bioactivation of miserotoxin. The first occurs in the rumen and the second probably occurs in the 
liver. Hydrolysis of the glycosidic bond and release of the aglycone by rumen microorganisms is the essential first step since the glycoside itself was shown to be relatively innocuous (Majak et al. 1983). Enzymatic oxidation of the aglycone to 3-nitropropionic acid (NPA) by hepatic alcohol dehydrogenase is also essential since inhibitors of this enzyme suppressed the oxidation and protected rats from a lethal injection of the aglycone (Pass et al. 1985). The absorption of the aglycone from the rumen and the subsequent oxidation can occur very rapidly in cattle and sheep, as evidenced by the early appearance of NPA in the circulatory system following an intraruminal dose of the aglycone or glycoside (Majak et al. 1984, Pass et al. 1984).

Rumen microorganisms also have the capacity to detoxify $\mathrm{NPOH}$ and rumen bacteria capable of this degradation have been identified (Majak and Cheng 1981, Cheng et al. 1988). Extensive in vitro studies have shown that the rates of detoxification can vary with animal diet (Majak et al. 1982, 1986a). For example, range diets containing Kentucky bluegrass (Poa pratensis) yielded much higher rates of detoxification than feedlot diets composed of corn silage or alfalfa hay. The in vivo experiments in this study were carried out to test the biological significance of the in vitro assays. A significant increase in microbial detoxification in the rumen should result in a significant decrease in the circulating levels of NPA.

\section{In Vivo Trials}

The absorption studies on miserotoxin were conducted during 1984 with 4 rumen-fistulated Hereford steers maintained on 3 successive diets beginning with alfalfa hay which was supplemented with molasses containing $1 \%$ nitroethane. Earlier studies had shown that this synthetic analogue of NPOH can enhance the degradation of NPOH by ruminal microorganisms, probably through metabolic induction (Majak et al. 1986a). The second diet consisted of alfalfa hay without the supplement and the third successive diet was corn silage. During the consumption of each diet, individual animals were challenged with freeze-dried timber milkvetch given intraruminally at $20 \mathrm{mg} \mathrm{NPOH} / \mathrm{kg}$ body weight, approximately one half the lethal dose. Each animal was fasted 20 hours before the day of each challenge.

In vitro studies with rumen fluid using the protocol of Majak et al. (1986a) were conducted concurrently to determine microbial rates of detoxification. In vivo disappearance of $\mathrm{NPOH}$ from the rumen was determined spectrophotometrically, expressed in terms of an exponential decay, and the half-life of NPOH in the rumen was calculated from the first order rate constant (Majak et al. 1984). The possibility that absorption rates could be affected by rumen clearance rates was not overlooked. The water soluble marker Co.EDTA was used to concurrently determine the rate of passage of the liquid phase of rumen contents as described previously (Majak et al. 1986b). The marker was given at $10.7 \mathrm{mg}$ $\mathrm{Co} / \mathrm{kg}$ body weight, 4 hours before the milkvetch dose.

Blood samples were collected before the milkvetch dose and then at $0.25,0.5,0.75,1,1.5,2$, and 3 hours after the dose to determine circulating levels of NPA by high pressure liquid chromatography (HPLC) (Muir and Majak 1984). The absorption of NPOH from the rumen was estimated by the plasma concentrations of NPA expressed in terms of the area under the blood concentration time curve (AUC). The AUC) reflects the total amount of toxin that is absorbed and the assumption is made that the changes in plasma toxin concentration quantitatively reflect the changes occurring in toxin concentrations in other body fluids and tissues (Dvorchik and Vesell 1976). The AUC, calculated by the trapezoidal rule (Wylie 1953), consolidated the repeated measures on toxin concentration for each animal on each diet. This variable was then examined by analysis of variance to determine differences among diets.

The absorption and excretion of NPOH in cattle was further examined in a second experiment in 1989 when 4 rumen-fistulated Hereford cows, maintained on orchardgrass hay, were given timber milkvetch at $15 \mathrm{mg} \mathrm{NPOH} / \mathrm{kg}$ body weight. The NPA levels in plasma and urine were determined by HPLC utilizing disposable extraction columns for rapid sample preparation (Majak and McDiarmid 1990). Sampling times were extended to 4 and 5 hours after the dose.

\section{Results}

Figure 1 shows the in vivo disappearance of NPOH in the rumen of cattle on 3 consecutive diets. Differences in rates of disappearance were detected among diets $(P<0.05)$ and the shortest half-life for NPOH $(0.75 \mathrm{~h})$ was observed in the alfalfa diet supplemented with nitroethane. For the unsupplemented diets, the NPOH halflife varied from 1.67 hours (corn silage) to 2.3 hours (alfalfa hay) ( $S E=0.13$ ). The possibility was considered that the differential rates of disappearance could be related to differences in rumen

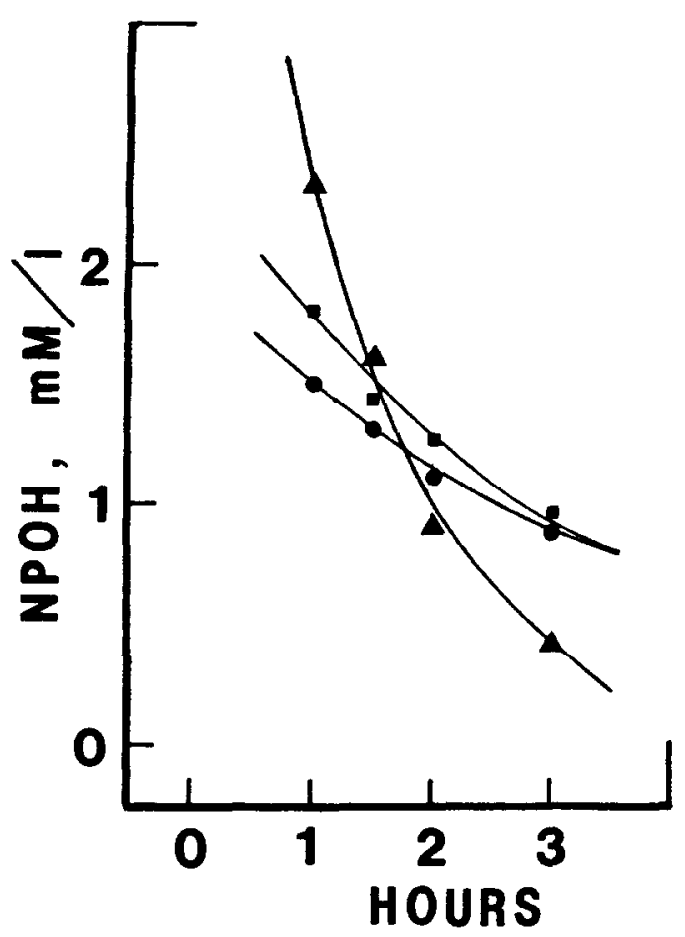

Fig. 1. Average rate of disappearance of NPOH in the rumen of 4 steers dosed intraruminally with timber milkvetch at $20 \mathrm{mg} \mathrm{NPOH} / \mathrm{kg}$ body weight. The cattle were maintained on 3 consecutive diets: alfalfa hay supplemented with molasses containing nitroethane $(\Delta)$; alfalia hay alone ( $\bullet$ ); and corn silage ( $\square$ ). Exponential curves were fitted using non-linear regression. Each value is the mean of 4 determinations; SE = 0.18.

clearance rates. However, there were no differences among diets in the half-life of the water-soluble marker, Co.EDTA $(P>0.05)$. The average half-life of Co.EDTA varied from 18.3 hours for the corn silage diet to 21.9 hours for the unsupplemented hay diet and the supplemented diet was intermediate at 19.7 hours but not detectably different from the other 2 . Thus the differences in rates of NPOH disappearance in vivo (Fig. 1) were probably due to differences in rates of microbial activity. This was confirmed when the in vitro rates of NPOH detoxification were compared. The highest in vitro detoxification rate $(P<0.05)$ was obtained with rumen inocula from the supplemented diet $\left(185 \mathrm{nM} \mathrm{ml}^{-1}\right.$ hour $\left.{ }^{-1}\right)$ but lower rates ( 66 to $89 \mathrm{nM} \mathrm{ml}^{-1}$ hour ${ }^{-1}$ ) were obtained with the unsupplemented diets $(\mathrm{SE}=34)$. 
When the AUC of NPA in plasma was examined, differences among diets were not detected during the initial phase $(0$ to 0.75 hour) when there is a rapid release of NPOH from freeze-dried milkvetch tissue. However, it should be noted that under grazing conditions, the release of NPOH from fresh forage tissue would be much more gradual. The average AUC's were significantly different $(P<0.05)$ during the elimination phase ( 1 to 3 hours) when the AUC was smaller in the unsupplemented diet ( $35 \mathrm{nM}$ hour ml-1),

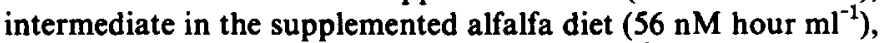
and larger in the corn silage diet $\left(83 \mathrm{nM}_{\text {hour ml}}{ }^{-1}\right)(\mathrm{SE}=11)$. These results indicate that the AUC can be reduced by more than $50 \%$ by the appropriate choice of diet. It should be emphasized that when elevated levels of AUC were encountered (such as the AUC's for the unsupplemented diets), the AUC was usually underestimated because plasma concentrations of the toxin had not reached zero by the end of the experiment (Fig. 2). In contrast, the AUC's for

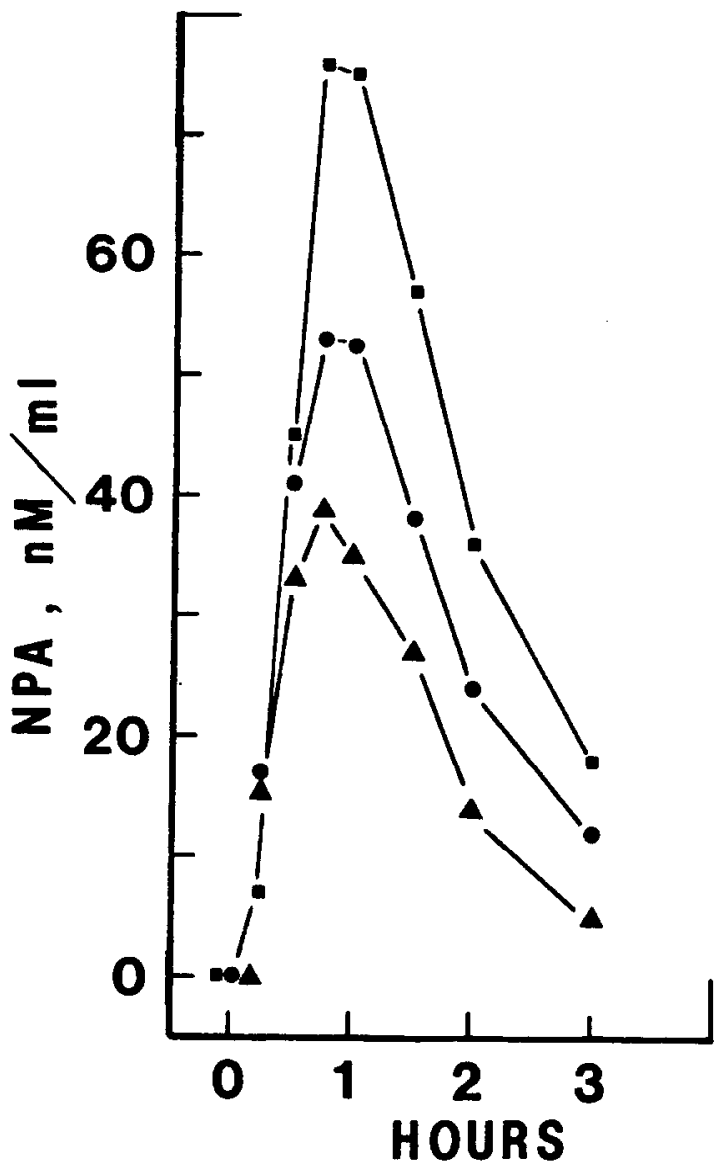

Fig. 2. A verage levels of plasma NPA in 4 steers dosed intraruminally with timber milkvetch at $20 \mathrm{mg} \mathrm{NPOH} / \mathrm{kg}$ body weight. The cattle were maintained on 3 consecutive diets: alfalfa hay supplemented with molasses containing nitroethane $(\Delta)$; alfalfa hay alone $(\bullet)$; and corn silage (D). Each value is the mean of 4 determinations; $\mathrm{SE}=10.1$.

cattle on supplemented diets were usually at or close to zero by this time. Thus the alfalfa-nitroethane diet, which enhanced microbial rates of detoxification, showed the lowest degree of NPOH absorption and the corn silage diet showed the highest degree of NPOH absorption.

The key role of NPA in the metabolism of aliphatic nitrotoxins (Majak and Pass 1989) prompted studies on the urinary excretion of the metabolite. Initially, analytical methods were developed to detect NPA in urine when it was given intravenously to cattle (Majak and McDiarmid 1990). These methods were then applied to the detection of NPA when timber milkvetch was given intra- ruminally. The dose was reduced from 20 to $15 \mathrm{mg} \mathrm{NPOH} / \mathrm{kg}$ to further test the sensitivity of the procedures. Table 1 shows that NPA can be readily detected at this dosage in both bovine plasma and urine. In previous studies, NPA levels in plasma and urine were highly correlated $(r=>0.96)$ for each animal when NPA was given intravenously (Majak and McDiarmid 1990). The individual correlations for the data in Table 1 were lower $(0.76-0.95)$ and this

Table 1. Detectable levels of NPA in the plasma and urine of 4 cows given timber milkvetch at $15 \mathrm{mg} \mathrm{NPOH} / \mathrm{kg}$ body weight. Levels were determined 0.5 to 5 hour after giving the intraruminal dose.

\begin{tabular}{|c|c|c|c|c|}
\hline \multirow[b]{2}{*}{ Cow no. } & \multicolumn{2}{|c|}{ Plasma } & \multicolumn{2}{|c|}{ Urine } \\
\hline & Mean & Range & Mean & Range \\
\hline & \multicolumn{4}{|c|}{ 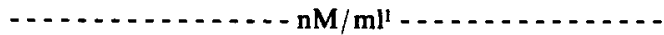 } \\
\hline 1 & $19(3)^{2}$ & $11-28$ & $346(3)$ & $254-490$ \\
\hline 2 & $13(5)$ & $3-23$ & $379(5)$ & $55-761$ \\
\hline 3 & $35(6)$ & $9-55$ & $383(6)$ & $172-621$ \\
\hline 4 & $53(4)$ & 4-67 & $336(4)$ & $47-582$ \\
\hline
\end{tabular}

$11 \mathrm{ppm} \mathrm{NPA}=8.4 \mathrm{nM} / \mathrm{ml}$.

${ }^{2}$ Number of observations.

might be attributed to delays in absorption caused by mixing and dispersion of the freeze-dried milkvetch tissue in rumen contents. Nevertheless, the elevated levels of NPA in urine compared to plasma (Table 1) suggest that the analytical methods for urine can be used to monitor cattle suspected of poisoning by nitro-bearing plants under field conditions and possibly to diagnose fatal poisoning.

\section{Prunasin}

\section{Metabolism and Absorption}

Prunasin is a major constituent in a number of browse species including chokecherry and serviceberry, where the glycoside can exceed $7 \%$ of the dry matter in leaves and $3 \%$ of the dry matter in twigs (Brooke et al. 1988, Majak et al. 1981). Many other members of the Rosaceae also contain prunasin (Seigler 1976).

Two steps are involved in the degradation of cyanogenic monosaccharides, such as prunasin, which produce the toxic agent, hydrogen cyanide (HCN), in rumen contents. Enzymatic hydrolysis of the glycosidic bond occurs first and then the HCN dissociates from the aglycone nonenzymatically. The spontaneous dissociation of the prunasin aglycone, mandelonitrile, was examined in rumen fluid and the dissociation was found to be $\mathrm{pH}$-dependent (Majak et al. 1990). Much higher rates of dissociation occurred at $\mathrm{pH}>6$ but the rate of $\mathrm{HCN}$ dissociation was almost negligible at $\mathrm{pH}$ 5. The $\mathrm{pH}$ of rumen fluid can exceed 7 during extended periods of fasting but it is depressed during feeding and digestion when volatile fatty acids are being produced during fermentation. Accordingly, the $\mathrm{pH}$ dependent step should have a significant impact on the overall rate of HCN production. This was validated when rates of cyanogenesis were examined diurnally. The highest rates of $\mathrm{HCN}$ production were associated with rumen inocula from cattle that had been fasted for 24 hours (Majak et al. 1990). This indicated that these animals would be most susceptible to poisoning by cyanogenic forages because the rates of $\mathrm{HCN}$ production and absorption could well exceed the rates of $\mathrm{HCN}$ detoxification. The overall rate of $\mathrm{HCN}$ production in the rumen was also found to be dependent on the animals' diet. Good quality forage yielded inocula with high rates of $\mathrm{HCN}$ production but grain diets (which lowered ruminal $\mathrm{pH}$ ) and poor quality hay reduced $\mathrm{HCN}$ production (Majak et al. 1990, Majak and Cheng 1987).

\section{In Vivo Trials}

An attempt was made to monitor the different pools of $\mathrm{HCN}$ in circulating blood to determine the degree and rate of HCN absorp- 
tion from the reticulo-rumen. These metabolic studies on prunasin were conducted in conjunction with earlier studies on rates of cyanogenesis in the bovine rumen (Majak and Cheng 1984). Cattle were dosed intraruminally with serviceberry twigs at $2.5 \mathrm{mg}$ $\mathrm{HCN} / \mathrm{kg}$ body weight, a dose that is approximately one-half the lethal dose of $\mathrm{HCN}$ as the cyanogenic glycoside, prunasin (Majak et al. 1980).

The frozen twigs were processed, administered intraruminally to 4 rumen-fistulated Hereford heifers maintained on alfalfa hay, and blood samples were collected as described previously (Majak et al. 1980). Blood samples were obtained before giving the serviceberry dose and then at $0.25,0.5,1,1.5,2,2.5,3,3.5,4,5$, and 6 hours after a dose. The blood samples were incubated for 3 hours at $37^{\circ} \mathrm{C}$ in Conway microdiffusion dishes; the free or bound HCN was trapped in alkali and analyzed with the pyridine-barbituric acid reagent (Lambert et al. 1975). Bound $\mathrm{HCN}$ was released with $10 \%$ $\mathrm{H}_{2} \mathrm{SO}_{4}$ (Pettigrew and Fell 1973). Plasma was treated with 6 volumes of ethanol to precipitate protein and plasma thiocyanate (the detoxified form of HCN) was then determined as described previously (Majak and Cheng 1984). Similar procedures were used for determining thiocyanate in urine.

\section{Results}

The rates of $\mathrm{HCN}$ disappearance from the rumen were reported earlier (Majak and Cheng 1984). Expressed in terms of half-life, they ranged from 0.91 hour to 3.54 hours when cattle were maintained on alfalfa hay. This large variation in half-life within a diet would be partly attributed to the physical properties of HCN, which is very soluble in rumen contents but also volatile. The precondition of the rumen could well determine the degree to which $\mathrm{HCN}$ is absorbed or exhaled. Retention of $\mathrm{HCN}$ in rumen contents, due to its solubility, would favor absorption. On the other hand, the release of $\mathrm{HCN}$ from rumen contents could be affected by microbial rates of gas production and the frequency of eructation.

Free $\mathrm{HCN}$ was detected only at very low levels in blood $(<1$ ppm) and it showed a high degree of variation among animals (Table 2). Levels of bound HCN (the pool of $\mathrm{HCN}$ that is released

Table 2. Average concentration of free and bound $\mathrm{HCN}$ and average rate of thiocyanate formation in blood after giving cattle mulched serviceberry browse at $2.5 \mathrm{mg} \mathrm{HCN} / \mathrm{kg}$ body weight. Blood samples were collected over a period of 6 hour following the intraruminal dose. The values are shown in equivalents of HCN.

\begin{tabular}{lccc}
\hline \hline Cow no. & Free HCN & Bound HCN & Thiocyanate \\
\hline & $\left(\mathrm{nM} \mathrm{ml}^{-1}\right)^{\prime}$ & $\left(\mathrm{nM} \mathrm{ml}^{-1}\right)$ & $\left(\mathrm{nM} \mathrm{m}^{-1}\right.$ hour $\left.^{-1}\right)$ \\
5 & $0.73 \pm 0.27^{2}$ & $26.5 \pm 3.92$ & $17.8(0.854)^{3}$ \\
6 & $1.88 \pm 0.35$ & $33.8 \pm 2.11$ & $11.7(0.956)$ \\
7 & $20.8 \pm 1.65$ & $201.9 \pm 19.6$ & $14.3(0.872)$ \\
8 & $4.04 \pm 1.23$ & $52.0 \pm 9.35$ & $21.2(0.918)$ \\
\hline
\end{tabular}

$1 \mathrm{ppm} \mathrm{HCN}=37 \mathrm{nM} / \mathrm{ml}$.

${ }^{2} \mathrm{SE}, \mathrm{n}=12$.

${ }^{3}$ Linear correlation coefficient for rate determination.

when blood is acidified) were much higher but they did not show a consistent pattern during the 6-hour sampling period so the values are shown as simple averages (Table 2). Heifer 7 showed much higher plasma HCN levels than the other 3 animals (Table 2). Higher plasma levels at similar doses of serviceberry were also detected in earlier studies (Majak et al. 1980). Thus a simple relationship between the dynamics of the glycoside in the rumen and the circulating levels of $\mathrm{HCN}$ in the blood was not observed. In short, it was possible to detect and quantify circulating pools of $\mathrm{HCN}$ but its volatility and reactivity with macromolecules (Lundquist et al. 1985) precluded direct observations on rates of $\mathrm{HCN}$ absorption from the rumen. The most consistent form of $\mathrm{HCN}$ in blood was the thiocyanate pool, as it showed a rather stable rate of increase (Table 2) which can be attributed to $\mathrm{HCN}$ detoxification through the enzymatic action of rhodanese (EC 2.8.1.1).

The pools of $\mathrm{HCN}$ were also examined in the urine of 3 of the animals and the most significant finding was the detection of high levels of thiocyanate at 24 to 48 hours after the dose. The range of values (in equivalents of $\mathrm{HCN}$ ) for each animal was as follows: 200-963 (cow 5), 787-2,200 (cow 6) and 559-1,629 nM/ml (cow 7). These high, delayed levels in urine suggest that urinary thiocyanate analysis could well be used as a diagnostic procedure for detecting $\mathrm{HCN}$ poisoning in cattle.

\section{Summary and Practical Implications}

In summary, prunasin and miserotoxin share a common feature as glycosides, in that they are both $\beta$-D-glucosides and must be hydrolyzed by the hydrolytic enzyme $\beta$-glucosidase (EC 3.2.1.21) before becoming toxic. The hydrolytic enzyme is a component of many cyanogenic plants but it is unlikely that the plant enzyme is active in rumen contents where soluble plant proteins are rapidly degraded by rumen microorganisms. However, rumen bacteria have the capacity to hydrolyze $\beta$-D-glucosides (Majak and Cheng 1984,1987 ) and to utilize the glucose as an energy source. The toxic aglycone can then be rapidly absorbed or further metabolized in rumen contents. Ruminal metabolism of NPOH can result in detoxification and reduced absorption of the aglycone from the reticulo-rumen. Ruminal detoxification of $\mathrm{HCN}$ is also possible (Majak and Cheng 1984) but HCN is more likely to be absorbed into the circulatory system where it rapidly binds to macromolecules. In addition, products of aglycone metabolism (NPA or thiocyanate) can also be detected and quantified in bovine urine for possible testing in cases of poisoning.

In the absence of hydrolysis, glycosides such as miserotoxin and prunasin are relatively innocuous since they can be absorbed and excreted intact (Majak and Pass 1989). Cyanide, for example, is considered to be lethal at $2 \mathrm{mg} / \mathrm{kg}$ body weight $(0.08 \mathrm{mM} / \mathrm{kg})$ but the $\mathrm{LD}_{50}$ of prunasin was found to be $560 \mathrm{mg} / \mathrm{kg}(1.9 \mathrm{mM} / \mathrm{kg})$, a large portion of it being excreted intact when given to rats orally (Sakata et al. 1987). Inhibition of microbial $\beta$-glycosidase might provide a means of protecting ruminants from toxic glycosides (Majak and Pass 1989). The factors that control the level of $\beta$ glucosidase in the rumen need to be further examined because this enzyme plays a fundamental role in the biotransformation of toxic glycosides.

\section{Literature Cited}

Brooke, B.M., R.E. McDiarmid, and W. Majak. 1988. The cyanide potential in two varieties of Amelanchier alnifolia. Can. J. Plant Sci. 68:543-547.

Cheeke, P.R. 1989. Toxicants of plant origin. Vol. II Glycosides. CRC Press Inc. Boca Raton, Fla.

Chenge, K.-J., R.C. Phillippe, and W. Majak. 1988. Identification of rumen bacteria that anaerobically degrade nitrite. Can. J. Microbiol. 34:1099-1102.

Dvorchik, B.H., and E.S. Vesell. 1976. Pharmacokinetic interpretation of data gathered during therapeutic drug monitoring. Clin. Chem. 22:866-878.

Lambert, J.L., J. Ramasamy, and J.F. Paukstelis. 1975. Stable reagents for the colorimetric determination of cyanide by modified König reactions. Anal. Chem. 47:916-918.

Lundquist, P., H. Rosling, and B. Sorbo. 1985. Determination of cyanide in whole blood, erythrocytes, and plasma. Clin. Chem. 31:591-595.

Majak, W., and K.-J. Cheng. 1981. Identification of rumen bacteria that anaerobically degrade aliphatic nitrotoxins. Can. J. Microbiol. 27:646-650.

Majak, W., and K.-J. Cheng. 1984. Cyanogenesis in bovine rumen fluid and pure cultures of rumen bacteria. J. Anim. Sci. 59:784-789. 
Majak, W., and K.-J. Cheng. 1987. Hydrolysis of the cyanogenic glycosides amygdalin, prunasin and linamarin by ruminal microorganisms. Can. J. Anim. Sci. 67:1133-1137.

Majak, W., K.-J. Cheng, and J.W. Hall. 1982. The effect of cattle diet on the metabolism of 3-nitropropanol by ruminal microorganisms. Can. J. Anim. Sci. 62:855-860.

Majak, W., K.-J. Cheng, and J.W. Hall. 1986a. Enhanced degradation of 3-nitropropanol by ruminal microorganisms. J. Anim. Sci. 62:1072-1080.

Majak, W., J.W. Hall, L.M. Rode, and C.M. Kalnin. 1986b. Rumen clearance rates in relation to the occurrence of alfalfa bloat in cattle. 1 . Passage of water soluble markers. J. Dairy Sci. 69:1560-1567.

Majak, W., and R.E. McDiarmid. 1990. Detection and quantitative determination of 3-nitropropionic acid in bovine urine. Toxicol. Lett. 50:213-220.

Majak, W., R.E. McDiarmid, and J.W. Hall. 1981. The cyanide potential of saskatoon serviceberry (Amelanchier alnifolia) and chokecherry (Prunus virginiana). Can. J. Anim. Sci. 61:681-686.

Majak, W., R.E. McDiarmid, and J.W. Hal, and K.-J. Cheng. 1990. Factors that determine rates of cyanogenesis in bovine rumen fluid in vitro. J. Anim. Sci. 68:1648-1655.

Majak, W., and M.A. Pass. 1989. Aliphatic nitrocompounds. p. 143-159. In:P.R. Cheeke (ed.), Toxicants of plant origin Vol. Il Glycosides. CRC Press Inc., Boca Raton, Fla.

Majak, W., M.A. Pass, and F.J. Madryga. 1983. Toxicity of miserotoxin and its aglycone (3-nitroporpanol) to rats. Toxicol. Lett. 19:171-178.

Majak, W., M.A. Pass, A.D. Muir, and L.M. Rode. 1984. Absorption of 3-nitropropanol (miserotoxin aglycone) from the compound stomach of cattle. Toxicol Lett. 23:9-15.
Majak, W., T. Udenberg, L.J. Clark, and A. McLean. 1980. Toxicity of saskatoon serviceberry to cattle. Can. Vet. J. 21:74-76.

Muir, A.D., and W. Majak. 1984. Quantitative determination of 3nitropropionic acid and 3-nitropropanol in plasma by HPLC. Toxicol. Lett. 20:133-136.

Pass, M.A., W. Majak, A.D. Muir, and G.S. Yost. 1984. Absorption of 3-nitropropanol and 3-nitropropionic acid from the digestive system of sheep. Toxicol. Lett. 23:1-7.

Pass, M.A., A.D. Muir, W. Majak, and G.S. Yost. 1985. Effect of alcohol and aldehyde dehydrogenase inhibitors on the toxicity of 3-nitropropanol in rats. Toxicol. Appl. Pharmacol. 78:310-315.

Pettigrew, A.R., and G.S. Fell. 1973. Microdiffusion method for estimation of cyanide in whole blood and its application to the study of conversion of cyanide to thiocynate. Clin. Chem. 19:466-471.

Quinton, D.A., W. Majak, and J.W. Hall. 1989. The effect of cattle grazing on the growth and miserotoxin content of Columbia milkvetch. J. Range Manage. 42:368-371.

Sakata, M., A. Yoshida, C. Yuasa, K. Sakata, and M. Haga. 1987. Toxicity of D.L. Mandelonitrile- $\beta$-D-glycoside, "Prulaurasin" in rat. J. Toxicolog. Sci. 12:47-55.

Seigler, D.S. 1976. Plants of northeastern United States that produce cyanogenic compounds. Econ. Bot. 30:395-407.

Williams, M.C. 1982. 3-Nitropropionic acid and 3-nitro-1-propanol in species of Astragalus. Can. J. Bot. 60:1956-1963.

Williams, M.C., and E. Gómez-Sosa. 1986. Toxic nitro compounds in species of Astragalus (Fabaceae) in Argentina. J. Range Manage. 39:341-344.

Wylie, C.R. Jr. 1953. Calculus. McGraw-Hill Book Co. New York. 